Agata Šega

Ljubljana, Eslovenia

\title{
OTRO MODO DE JUGAR A LA RAYUELA
}

Lo malo en vos -dijo Traveler- es que cualquier problema lo retrotraés a la infancia. Ya estoy harto de decirte que leas un poco a Jung, che.

(Rayuela, 41:391)

Thus, what apears in the vision is the imagery of the collective unconscious. This is the matrix of consciousness and has its oqwn inbom structure.

(Jung)

En su artículo La búsqueda del "yo" al "nosotros": Génesis y definición del tema del perseguidor en Cortazar Lida Aronne Amestoy afirma que un claro concepto técnico para definir el itinerario de la búsqueda cortazariana es "la individuación" y que partiendo de una división existencial tipicamente esquizofrénica, toda la aventura cortazariana parece cubrir las sucesivas fases de un proceso de integracion de lo consciente y de lo inconsciente, del mito y del intelecto. La autora subraya el hecho de que el proceso del crecimiento interno no posee otra dirección que la impuesta por arquetipos humanos naturales y no reconoce más iniciador que la consciencia personal. ${ }^{1}$

El teórico del proceso de la integración de lo consciente y de lo inconsciente con la ayuda de arquetipos naturales, es decir del así llamado proceso de individuación, es Carl Gustav Jung. Nos apoyaremos entonces en cierta medida en su teoría para resolver el problema que nos planteamos en este artículo: trataremos de contestar en qué forma y de qué manera se expresan en Rayuela algunos de los conceptos simbólicos arquetípicos que hacen parte del proceso de individuación.

1. Explican los junguianos que la meta del proceso de individuación es la realización de la unicidad del hombre individual, del acuerdo consciente con el propio centro interior, es decir, con la totalidad de la psique que Jung llama el sí-mismo y de la cual el ego, o la parte consciente representa sólo una pequeña parte. Otros dos aspectos ${ }^{2}$ de la psique que

1 IF, p. 382.

2 Jung I. 
aparecen en los sueños y en las visiones son el ánima, una figura suprema del género opuesto que personifica todas las tendencias de este género en la psique de la persona analizada, y la sombra, una figura del mismo género que el ego, que produce la sensación de miedo o repugnancia. Su función es precisamente representar las cualidades reprimidas o inconscientes de la personalidad, es decir, su lado opuesto desconocido incorporándolo en la totalidad de la psique.

Para superar la crisis que puede causar el desacuerdo entre el ego y el si-mismo el hombre debería dirigir su atención a su propio inconsciente. La teoría junguiana afirma que la consecuencia de tal introspección puede ser a menudo un torrente de imágenes simbólicas que resultan útiles en el proceso de individuación. Los símbolos son, como afirma Jung, intentos naturales para reconciliar y unir los opuestos naturales dentro de la psique, ${ }^{3}$ Claro está que en caso de un artista los sueños y las visiones provenientes del inconsciente penetran también en la esfera de la vigilia y se expresan en su obra.

Cortázar mismo dice que sus cuentos son una especie de autopsicoanálisis. ${ }^{4}$ Harss define Rayuela como una obra terapéutica $a^{5}$ y subraya el aspecto exorcista de la fantasía cortazariana. ${ }^{6}$ Afirma Evelyn Picon Garfield que el exorcismo de la obsesión tiene un papel importante en toda la obra de Cortazar. ${ }^{7}$

En Rayuela, a lo mejor más que en otras obras de Cortázar, nos encontramos constantemente con el concepto de la búsqueda que se acuerda perfectamente con la definición junguiana de la individuación. La búsqueda cortazariana aparece como el deseo del protagonista de lograr una reconciliación consigo mismo y con la realidad que habitaba (19:216). El buscador cortazariano no es, sino que busca ser, proyecta ser (62:524) constatando que sin poseerse no había posesión de la otredad (22:240) y tratando de encontrar su propia identidad para poder contactar con el mundo. Dice Cortázar en La vuelta al día en ochenta mundos que el mundo de adentro es la ruta inevitable para llegar de verdad al mundo exterior y descubrir que los dos serán uno cuando la alquimia de ese viaje de un nuevo hombre, el gran reconciliado. ${ }^{8}$ Una ruta entonces en la que las señales de tráfico y los indicadores son los símbolos.

2. La afirmación de los junguianos que el símbolo posee connotaciones específicas además de su significado corriente y obvio ${ }^{9}$ llama inmediatamente la atención por su semejanza con la definición de lo que los especialistas en Cortázar han llamado el agente mágico. $^{10}$

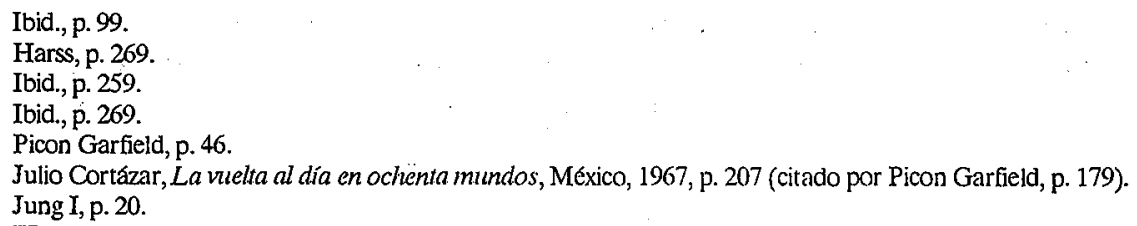


Según las palabras del mismo Cortázar, sus personajes creen que la realidad cotidiana enmascara una segunda realidad. ${ }^{11} \mathrm{La}$ fusión de estas dos realidades se ejerce siempre con la ayuda de un concepto-vínculo, sea personaje, animal, objeto, lugar, forma geométrica, juego o cualquier otra cosa, llamado el agente mágico. Agudizando la percepción y concentrándose en lo que le rodea, el personaje cortazariano llega a descubrir que los objetos triviales tienen una segunda cara:

En uno de sus libros Morelli habla del napoletano que se pasó años sentado a la puerta de su casa mirando un tomillo en el suelo. ... A lo mejor el napoletano era un idiota pero también pudo ser el inventor delmundo. (73: 545)

3. Visto todo eso no parece nada extraño si en Rayuela encontramos, bajo formas diferentes, un gran número de símbolos que pertenecen al proceso de individuación. Lida Aronne Amestoy nota en el artículo mencionado que la mujer cortazariana representa muchas veces la encarnación del ánima y menciona como uno de los ejemplos más típicos sobre todo a la Maga y también a Talita, dos figuras femeninas centrales de Rayuela ${ }^{\mathbf{1 2}}$ Claro está que podríamos continuar aplicando la teoría junguiana a otros personajes de la novela y afirmar, por ejemplo, que Traveler encarna la sombra de Horacio, o, más exacto, que Horacio, presentado en la segunda parte de la novela casi como un ser del otro mundo, un fantasma, encarna la sombra de su amigo y doppelgänger (56: 499) y llegar a la conclusión que el capítulo 56 representa la reelaboración literaria de la así llamada batalla por la liberación ${ }^{13}$, es decir, del conflicto entre el ego y su sombra. Sin embargo, dejaremos aparte el problema de la interpretación de los papeles que juegan los diferentes personajes en Rayuela desde el punto de vista de la teoría junguiana y trataremos de consagrarnos a continuación sobre todo a la explicación de algunos simbolizantes importantes para la comprensión del sistema simbólico establecido consciente- o inconscientemente por el escritor.

II.

El fin que persiguen los buscadores cortazarianos y que, en el fondo, se iguala al ideal de Baudelaire o al azur de Mallarmé, puede llamarse lo absoluto (9: 165), el reino (71: 542), el paraíso (18: 207), la salida (71: 540), el cielo (4: 146) - con minúscula o con mayúscula -, el lugar (123: 669), lo otro o el otro lado (93: 592), más alla (55: 485), detras (71: 537), Yonder (99: 617), la isla (71: 537), el kibbutz del deseo (36: 354) o, casi irónicamente, el gran asunto (90: 582). En el capítulo I hemos constatado que la búsquueda cortazariana representa la búsqueda del propio centro interior, del equilibrio entre lo consciente y lo inconsciente. En el análisis psicológico, la imagen arquetípica de este centro interior que aparece en los sueños y en las visiones de las personas cuyo equilibrio psíquico está amenazado, es un

11 Citado por Picon Garfield, p. 138.

12 Ibid., p. 382.

13 Jung I, p. 118. 
motivo nuclear, circular, cuadrangular o helicodial. Este motivo que muchos soñantes definen más tarde como el espíritu santo o dios representa una replica estructural del núcleo de la psique, es decir, del si-mismo. ${ }^{14}$

1. Para designar una estructura que es una representación simbólica del atomo nuclear de la psique humana, Jung empleó la palabra hindú mandala que significa círculo magico. ${ }^{15}$ Los tibetanos entienden ese círculo como lo que rodea; es decir, el centro buscado es uno mismo, el que lo construye a su alrededor. En la entrevista con Harss ${ }^{16}$, Cortázar confiesa que Rayuela debió originalmente titularse Mandala:

Cuando pensé en el libro, estaba obsesionado con la idea del mandala, en parte porque había estado leyendo muchas obras de antropologia y sobre todo de religión tibetana. Además habia visitado la India, donde pude ver cantidad de mandalas indios y japoneses.

El mandala, laberinto místico de los budistas, Cortázar lo explica ${ }^{17}$ como...

... un cuadro o un dibujo dividido en sectores, compartimientos o casillas - como la rayuela - en el que se concentra la atención y gracias al cual se facilita y estimula el cumplimiento de un progreso espiritual.

En lugar del mandala que representa el centro o círculo supremos, la imagen del universo, el viaje iniciático dividido en una serie de pruebas purificadoras, propone su versión prosaica: la rayuela, un juego infantil que pertenece a la experiencia común. Cortázar justifica así su decisión: ${ }^{18}$

Por su parte las rayuelas, como casi todos los juegos infantiles, son ceremonias que tienen un remoto origen místico y religioso. Ahora están desacralizados, por supuesto, pero conservan en el fondo algo de su antiguo valor sagrado. Por ejemplo, la rayuela que suele jugarse en la Argentina - y en Francia - muestra a la Tierra y el Cielo en los extremos opuestos del dibujo. Todos nos hemos entretenido de niños con esos juegos, pero en mi caso fueron desde el comienzo una verdadera obsesion.

2. En el capítulo 36, Cortázar enumera las formas posibles del dibujo de la rayuela: rayuela caracol, rayuela rectangular, rayuela de fantasía, poco usada (36: 367). La forma geométrica de los objetos de que Cortázar se sirve para evocar de modos diferentes el

14 Jung I, p. 225.

15 Jung II, p. V.

16 Harss, p. 266.

17 Ibid.

18 Ibid. 
contenido simbólico de la rayuela o del mandala, se aproxima siempre en Rayuela de una de las formas citadas, entre las que prevalece, sin duda, la forma de espiral.

La búsqueda del Cielo y del propio centro supone un movimiento circular, en forma de laberinto o espiral. Esta construcción geométrica es representada en Rayuela por diferentes objetos concretos: el ovillo (52: 466), el tornillo ya mencionado (73:545-546), la escalera de caracol en el sueño de Talita (45: 432) o el caracol con que Ronald compara a la Maga (142: 718). En el capítulo prescindible 110 que contiene la descripción de un sueño, tomada del libro Winter of artifice de Anaïs Nin, aparece una torre cuya estructura se asemeja a la de la molécula del ácido desoxiribonucléico que constituye el núcleo y el citoplasma de la célula viva:

El sueño estaba compuesto como una torre formada por capas sin fin que se alzaran y se perdieran en el infinito, o bajaran en círculos perdiéndose en las entrañas de la tierra. Cuando me arrastró en sus ondas la espiral comenzo, y esa espiral era un laberinto. No habia ni techo nifondo, ni paredes ni regreso. Pero había temas que se repetían con exactitud. (110: 647)

El hecho de que la forma de espiral tiene el sentido simbólico de mandala es conocido. iYqué espiral, el ser del hombre! exclama Gaston Bachelard en su libro La poetica del espacio y continúa: iEn esta espiral, cuántos dinamismos se invierten! Ya no se sabe en seguida si uno corre al centro o si se evade de él. ${ }^{19}$ Lo mismo ocurre en Rayuela: para Oliveira, caer es lo mismo que ascender (Fijate que sime tiro - dijo Oliveira -, voy a caer justo en el Cielo.; 56: 504), volver es lo mismo que ir (Se dio cuenta de que la vuelta era realmente la ida en más de un sentido.; 40: 383). La búsqueda se parece a una espiral ascendente que va hacia arriba mientras que, simultáneamente, vuelve otra vez al mismo punto y el protagonista nunca sabe si está realmente avanzado hacia el centro o si se está alejando de él. Dicho con palabras de Bachelard: ${ }^{20}$

Ainsi, l'être spiralé, qui se désigne extérieurement comme un centre bien investi, jamais n'atteindra son centre. L'être de l'homme est un être defixie.

3. En general, los contenidos simbólicos de Rayuela se concentran más o menos alrededor de tres temas arquetípicos principales con remota y amplia tradición en la cultura occidental que se relacionan todos con el proceso de individuación. Se trata del tema del sacrificio y de la muerte, del descenso al infierno y, finalmente, del tema del laberinto y de la lucha contra el monstruo. En la simbología de la mitología clásica el laberinto se considera como el equivalente del mandala que pertenece a la mitología oriental. Las siguientes

19 Bachelard I, p. 193.

20 Ibid. 
palabras de Nietzsche ${ }^{21}$ confirman que Cortázar no es ni el primero ni el único que lo ha intuído:

Wollten und wagten wir eine Architekturnach unserer Seelen-Art (wir sind zu feige dazu!) - su müsste das Labyrinth unser Vorbild sein!

Desde 1949, cuando Cortázar presenta su versión del mito de Teseo y del laberinto en Los Reyes, la simbología conexionada con este tema resurge constantemente en su obra. El autor explica a Luis Harss ${ }^{\mathbf{2 2}}$ la fascinación que ejerce el laberinto sobre él desde la niñez:

... desde niño, todo lo que tuviera vinculación con un laberinto me resulta fascinador. Creo que eso se refleja en mucho de lo que llevo escrito. De pequeño fabricaba laberintos en el jardín de mi casa.... Es sabido que los niños gustan de imponerse ciertos rituales: saltar con un pie, con los dos pies... Mi laberinto era un camino que yo tenía perfectamente trazado, y que consistía principalmente en cruzar de una vereda a otra a lo largo del camino. ... Varios años viví obsesionado por esta ceremonia, porque era una ceremonia.

El recurso a la mitología clásica se advierte como tendencia general en la obra de un gran número de autores importantes del siglo XX, pero según Roberto González Echeverría no se trataría de un espíritu neoclásico, sino más bien de una búsqueda filologica de una mitología de los orígenes. ${ }^{23}$ Su observación está de acuerdo con lo que dice Jung en relación a ello: ${ }^{24}$

It is ... to be expected that the poet will tum to mythological figures in order to give suitable expression to his experience. Nothing would be more mistaken than to suppose that he is working with second-hand material. On the contrary, the primordial experience is the source of his creativeness, but it is so dark and amorphous that it requires the related mythological imagery to give it form.

4. Hay que decir, sin embargo, que al comienzo del libro el juego de la rayuela no tiene aún el significado simbólico del mandala o del laberinto, sino que el autor se lo va concediendo progresivamente. Veamos ahora de manera un poco más detallada cómo se ejerce esta intensificación de la significación, esta simbolificación del concepto de la rayuela.

En la primera parte de la novela este juego se menciona sólo un par de veces al pasar, como si fuera por casualidad. Aparece por primera vez en la descripción de los paseos que dan Horacio y la Maga por París,

21 Nietzsche, p. 152.

22 Harss, p. 265.

23 Roberto González Echeverría, Los Reyes: Mitología de la obra literaria de Cortázar, IF, p. 205.

24 Jung III, "On the relation of the analytical psychology to poetry", p. 96. 
... deteniéndose en las placitas para besarse en los bancos o mirar las rayuelas, los ritos infantiles del guijarro y el salto sobre un pie para llegar al Cielo (4: 145)

Por la segunda vez, el narrador habla indirectamente de este juego de modo que sólo un lector atento puede captar la alusión:

-Lo absoluto - decia la Maga, pateando una piedrita de charco en charco -. ¿Qué es un absoluto, Horacio? (9: 165)

Solamente en el capítulo 36, después de haber descendido simbólicamente al infierno ${ }^{25}$, Horacio, y con él el lector, se dan cuenta de la importancia de la rayuela y de su profundo significado simbólico. Después de una reflexión profunda, esta imagen ayuda a Horacio a unificar las oposiciones, a situar el cielo en la tierra:

... no ya subir al cielo (subir, palabra hipocrita, cielo, flatus vocis), sino caminar con pasos de hombre por una tierra de hombres hacia el kibbutz alla lejos pero en el mismo plano, como el Cielo estaba en el mismo plano que la Tierra en la acera roñosa de los juegos... (36:369)

La rayuela del lado de acá que se sitúa en el jardín del manicomio donde trabajan Oliveira, Traveler y Talita tiene ya las características de un círculo mágico: se muestra capaz de transfigurar a Talita en la Maga. Para destacar su poder místico, Cortázar hace resplandecer misteriosamente el dibujo de tiza en la oscuridad (51: 466, 54: 473). Este detalle revela la importancia que el autor atribuye al símbolo de la rayuela haciéndonos pensar al teorema cósmico. Tout ce que brille voit, establecido por Gaston Bachelard en su libro La poétique de l'espace. ${ }^{26}$ Todo el valor del símbolismo se revela en el último párrafo del capítulo 54 cuando Oliveira toma a Talita por la Maga y, besándola, alcanza la última casilla de la rayuela que en aquel momento se muestra equivalente al centro del mandala (54: 582), al Ygdrassil vertiginoso (ibid.) y simboliza la reconciliación final de todos los opuestos.

\section{III.}

El simbolismo de Rayuela es sin duda extremadamente rico y complicado. En Cortázar, como también en otros artistas, las nociones de naturaleza más diversa asumen significación simbólica: Personajes, animales, juegos, formas abstractas, lugares, movimientos, cosas hechas por el hombre, cosas que existen en la naturaleza y fenómenos naturales, música, arte, colores, sonidos, nombres, números. Jung opina que tal variedad es

25 Margery A. Safir, Para un erotismo de la liberación: Notas sobre el comportamiento transgresivo en Rayuela y Libro de Manuel, IF, p. 228-229.

26 Bachelard I, p. 48. 
necesaria para que el artista pueda expresar de manera satisfactoria su visión, su experiencia primordial: ${ }^{27}$

Since the expression can never match the richness of the vision and can never exhaust its possibilities, the poet must have at his disposal a huge store of material if he is to communicate even a fraction of what he has glimpsed, and must make use of a difficult and contradictory images in order to express the strange paradoxes of his vision.

Se puede, sin embargo, discernir dos características principales del sistema simbólico de Rayuela.

1. La primera característica es, como llevamos dicho, que Cortázar evita a menudo los simbolizantes cargados de valor mítico y escatológico. En el libro esta tendencia se comenta con un poco de ironía:

Hacía rato que a Oliveira le importaban cosas sin importancia, y la ventaja de meditar con la atención fija en el jamito verde estaba en que a su pérfida inteligencia no se le ocumiría nunca adosarle al jarito verde nociones tales como las que nefariamente provocan las montañas, la luna, el horizonte, una chica puiber, un pájaro o un caballo. (19: 214)

Casi se podría decir que en Rayuela asistimos a una apoteosis de lo trivial: los contenidos simbólicos más profundos se encuentran representados por varios simbolizantes que a primera vista parecen completamente insignificativos, por ejemplo la rayuela, el jarro para cebar mate, el embudo y hasta el buzo de lavabos. Sin embargo se muestra al final que estos conceptos tienen el papel de intercesores entre los dos lados opuestos.

2. Por otra parte, Cortázar enriquece y complica su sistema simbólico con la utilización de un procedimiento que actúa en el sentido opuesto del antes mencionado y consiste en ridiculizar y banalizar lo mitológico y lo simbólico universalmente reconocido. Los símbolos tradicionales y universales conexionados con el simbolismo del mandala y de la búsqueda del si-mismo aparecen bajo disfraces modernos y hasta grotescos, en situaciones que aparentemente no tienen nada de simbólico. En el huevo frito entre podrido y petrificado (96:604) que los miembros del grupo llamado el Club de la Serpiente encuentran en el piso de Morelli, su leader espiritual, y terminan por echarlo a la basura, iquién podría ver el huevo como símbolo del caos primordial, del principio de la vida, de la resurrección y de la seguridad en el útero, el huevo cuyo simbolismo equivale al de la concha, del nido o de la casa? ${ }^{28}$ En el pez que Ossip Gregorovius ve nadar en el acuario de un bordel o en la paloma blanca, acariciada incansablemente por un loco en el manicomio de Buenos Aires, iquién

27 Jung III, ibid., p. 96.

28 Chevalier-Gheerbrant, pp. 213-215. 
podría reconocer dos símbolos telúricos paralelos, conexionados con el nacimiento y la resurrección? ? $^{29}$

La simbología de Rayuela arma entonces una trampa para el lector-hembra: Cortázar se sirve de dos mecanismos: el primero consiste en la demitologización de lo mítico, es decir en el uso muy amplio de los motivos mitológicos en situaciones imprevistas y en disfraces grotescos que los vuelven casi irreconocibles, y el segundo en una suerte de mitologización de lo cotidiano, por banal o marginal que parezca.

El resultado de la combinación de estos dos procedimientos es una variedad simbológica tan increíble que podríamos aplicar perfectamente a Rayuela sola la frase con la que Jung se refiere al material simbólico en el trabajo de varios autores: ${ }^{\mathbf{3 0}}$

Nothing is missing in the whole gamut that ranges from the ineffably sublime to the perversly grotesque.

El protagonista de la novela es un hombre que trata de evitar como la peste toda la sacralización de los juegos (5:154). Terminada la lectura, nos damos cuenta que su mensaje va precisamente en el sentido opuesto: los juegos ya son sacralizados, no hay nada que hacer.

Bibliografía.

Texto:

Cortázar, Julio, Rayuela, Madrid, edición de Andrés Amoros, Cátedra, Letras hispánicas, 1986.

Obras sobre Cortazar:

Harrs, Luis, Los nuestros, Buenos Aires ${ }^{8} 1978$.

Cortázar, Julio, La isla final (IF), Madrid, edición de J. Alazraki, I. Ivask y J. Marco, 1983.

Piocon Garfield, Evelyn, ¿Es Julio Cortázar un surrealista?, Madrid, 1975.

Otras obras:

Bachelard, Gaston, La poétique de l'espace (I), Paris, ${ }^{12} 1984$.

29 Ibid., pp. 169 y $557-559$.

30 Jung III, ibid., p. 97. 
Bachelard, Gaston, La poétique de la rêverie(II), Paris, ${ }^{9}, 1986$.

Chevalier, Jean, \& Alain Gheerbrant, Rjecnik simbola, Zagreb, 1987.

Jung, Carl Gustav, y otros, El hombre y sus símbolos (I), Madrid, ${ }^{2} 1974$.

Jung, Carl Gustav, Mandala symbolism (II), Princeton, ${ }^{3} 1973$.

Jung, Carl Gustav, The spinit in man, art and literature (The Collected works of C. G. Jung, vol. 15) (III), Princeton, ${ }^{4} 1978$.

Nietzsche, Friedrich, Morgenröte, Berlin - New York, 1971.

Povzetek

ŠE EN NAČIN, KAKO SE IGRAMO RISTANC

Avtorica se sklicuje na L. A. Amestoy, ki enači Cortázarjevo iskanje s tistim dogajanjem $v$ razvoju osebnosti, ki se $\mathrm{v}$ Jungovi teoriji imenuje proces individualizacije. Poskuša odgovoriti na vprašanje, $v$ obliki kakšnih simbolov se v Cortázarjevem romanu pojavljajo arhetipični koncepti, ki spadajo $\mathrm{k}$ temu procesu, in na kakšen način jih pisatelj vključuje v pripoved. Pri tem se osredotoci predvsem na koncept mandale in na njegove pojavne oblike, od katerih je ena prav ristanc, pojem, ki nam, potem ko smo ga srečali že v naslovu, začne postopoma razkrivati svoj simbolni pomen. 